DOI: 10.12731/2077-1770-2020-6-119-132

УДК 811.1

\title{
СОВРЕМЕННЫЕ ИНТЕРНЕТ-ТЕХНОЛОГИИ КАК МЕТОД ОБУЧЕНИЯ ГОВОРЕНИЮ В ПЕРИОД ДИСТАНЦИОННОГО ОБУЧЕНИЯ
}

Кудинова О.А.

Цель. Статья посвящена изучению теоретических вопросов обучения устной речи и разработке методов использования Интернет-технологий в процессе обучения устной речи.

Метод или методология проведения работы. Основу исследования составляют теоретическое изучение и обобщение научно-методической литературы, а такэе Интернет-ресурсы, связанные с темой исследования; используются общенаучные методы-анализ и обобщение.

Результаты. Результаты работы заключаются в том, что автор выявляет зависимость качества образовательного прочесса и его эффективность от правильной организачии использования Интернет-технологий на уроке, которые упрощают прочесс получения знаний. Автор делает предположение, что использование Интернет-технологшй способствует формированию речевых навыков и умений-ядра коммуникативной компетенции.

Область применения результатов. Результаты исследования помогут оптимизировать использование информационных технологий на занятиях по иностранному языку при обучении устной речи в высшей школе.

Ключевые слова: Интернет-технологии; обучение говорению; изучение иностранных языков; аудио и видео подкасты; выстая ступень образования.

\section{MODERN INTERNET TECHNOLOGIES AS A MEANS OF TEACHING SPEAKING WHILE DISTANCE LEARNING Kudinova O.A.}

Purpose. The article is devoted to the study of theoretical questions of teaching Speaking and the development of methods for using Internet technologies in the process of teaching Speaking. 
Methodology. The research is based on the theoretical study and synthesis of scientific and methodological literature, as well as Internet resources related to the research topic; general scientific methods-analysis and generalization are used.

Results. The results of the study are as follows: the author explicates the dependence of the quality of educational process and its effectiveness on the correct organization of the use of Internet technologies in the classroom which simplify the process of knowledge acquisition. The author suggests that the use of Internet technologies contributes to the formation of speech habits and skills - the core of communicative competence.

Practical implications. The results of the study will help optimize the use of information technologies for language teaching lessons in higher education.

Keywords: Internet technologies; teaching speaking; learning foreign languages; audio and video podcasts; high stage of education.

COVID-19 изменил отношение к образованию и изучению языков в частности. Многие студенты и другие люди, стремящиеся изучать иностранные языки, стараются найти удобные инновационные подходы к обучению, которые будут соответствовать их потребностям и отвечать требованиям жизни в рамках дистанционного формата обучения. В результате они готовы искать методы, которые будут менее трудоемкими, более интересными и эффективными.

В современном обществе воспитание личности, способной продуктивно и эффективно работать, является одной из важнейших задач. Именно поэтому учитель иностранного языка должен использовать соответствующие педагогические средства и технологии, которые будут направлены на формирование у учащихся интереса, любознательности, самостоятельности, настойчивости в учебном процессе. Интенсивное использование Интернет-технологий на уроках английского языка является одним из педагогических средств, направленных на развитие познавательной активности учащихся. 
В настоящее время традиционные образовательные средства занимают ведущее место в обучении иностранному языку, но благодаря использованию различных информационно-коммуникационных технологий учебную среду можно разнообразить видео, звуком и анимацией. Все эти факторы повышают мотивацию студентов к учебной деятельности и любознательность, повышают интерес к изучению иностранного языка. Повышение мотивации влияет на развитие речевых навыков студентов $[2 ; 3 ; 10 ; 14]$.

В исследовании уделяется внимание интересу студентов к Интернет-технологиям на уроках английского языка, особенно стоит упомянуть видео- и аудиоподкасты. Важно подчеркнуть, что качество образовательного процесса и его эффективность зависят от правильной организации использования Интернет-технологий на занятиях, которые могут упростить процесс получения знаний и облегчить формирование речевых навыков и умений, которые составляют основу коммуникативной компетенции.

B XXI в. трудно представить нашу жизнь без гаджетов с выходом в Интернет. Технологии проникли во все сферы нашей жизни, особенно в образование, создали плодотворную почву для того, чтобы люди учились всему, чему хотят и везде, где хотят. Гибкость и доступность становятся все более актуальными. Преподаватели должны быстро реагировать на ситуацию и реорганизовывать учебный процесс, сохраняя качество курса.

Необходимо создать совершенно новый подход к обучению, т.к. есть несколько препятствий, с которыми преподаватели столкнулись в процессе карантинного обучения. Во-первых, не все студенты готовы правильно выполнять свои задания без таких мотивационных факторов, как тесты, викторины или не могут не жульничать, зная, что никто не сможет проверить этот факт. Таким образом, крайне важно следить за студентами, чтобы убедиться, что учебный материал изучается, и в то же время поощрять их к тому, чтобы они преуспевали, не оказывая на них большого давления.

Конечная цель исследования - продемонстрировать, что использование Интернет-технологий является эффективным инструментом при обучении говорению. 
Современные студенты привыкли воспринимать информацию, знания и факты преимущественно посредством визуальной коммуникации и ярких образов, которые будут запоминающимися и легкими для понимания.

В настоящее время учителя испытывают трудности в обучении устной речи на английском языке. Литература поднимает вопрос о различных методах обучения основным видам речевой деятельности, составляющим понятие «устная речь», т. е. говорению и аудированию [9]. Современные университеты ставят перед собой задачи, определяющие актуальность развития устной речи. Образование направлено на формирование поликультурной личности студентов, владеющих системой знаний об иностранном языке как на уровне понимания, так и на уровне свободного общения.

Сегодня традиционные средства обучения занимают ведущее место в обучении иностранному языку, но благодаря использованию различных информационно-коммуникационных технологий, таких как видео, звук и анимация можно разнообразить образовательную среду. Все это непосредственно способствует повышению познавательной активности студентов, повышению мотивации в учебной деятельности, повышению интереса к изучению языка и иноязычной речи, поэтому использование всех ранее упомянутых технологий оказывает большое влияние на эмоциональную сферу студентов. В свою очередь, повышение мотивации и познавательной активности оказывает благотворное влияние на развитие устной речи учащегося.

Проанализировав методическую литературу, мы убедились, что методика обучения разговорной речи с использованием Интернет-технологий недостаточно развита. Учебная литература в основном посвящена изучению языка с использованием информационных и компьютерных технологий, но вопрос обучения с использованием Интернет-технологий до конца не изучен.

Устная речь - это форма речевой деятельности, которая включает в себя понимание устной речи и произнесение речевых высказываний в звуковой форме (говорение). Обучение устной речи - одна 
из самых сложных задач в процессе обучения английскому языку, т.к. устная речь - это широкое понятие, включающее в себя такие основные виды речевой деятельности, как чтение, аудирование, говорение, диалогическая и монологическая речь [1].

В процессе обучения устной речи возникает особая трудность, связанная с тем, что учащемуся необходимо овладеть и использовать языковой материал как средство общения, а не только для распознавания и идентификации. В дополнение к знанию синтаксической и морфологической структуры, учащийся должен уметь пользоваться сложной системой построения предложений, которая иногда не совпадает с обычными правилами построения предложений на родном языке.

Для того чтобы мотивировать познавательный интерес учащихся, преподаватель должен учитывать развитие учебных умений студентов, а также уровень их интеллектуального развития и интересов. В процессе изучения английского языка в университете можно изучить не только основы языка, но и понять, как вести беседу, читать тексты различного уровня сложности на предложенные темы, пересказывать и анализировать.

Г.А. Орлов дает свою характеристику устной речи. По его мнению, речь не является визуально наблюдаемой, мгновенной, эфемерной; она требует от говорящего меньше усилий, чем от пишущего, и обычно разворачивается достаточно свободно и быстро (средний темп английской разговорной речи превышает 160 слогов в минуту). Речь (как результат) записывается только в виде мысленного, вербального и речевого образа в памяти слушателя; результат может быть использован неучастниками данного коммуникативного акта только в том случае, если он записан с помощью технических средств (или дословного воспроизведения участниками коммуникативного акта [4, с. 66].

Таким образом, при обучении устной речи на английском языке, как и на любом другом языке, необходимо учитывать особенности каждого вида речевой деятельности. Только с учетом всех особенностей обучение устной речи в школе будет эффективным. 
Современный мир характеризуется стремительным обновлением происходящих процессов во всех сферах общественных отношений, а следовательно, и в сфере образования. Интернет становится главным средством обмена и распространения цифровой информации и одной из основных платформ для установления международных отношений. Этим объясняется возрастающая роль Интернет-технологий в системе образования, где процессы информатизации также происходят под влиянием социальных тенденций. В связи с этим к результатам освоения студентами образовательных программ стали предъявляться новые требования [6].

Интернет-технологии способствуют интеграции национальной системы образования в инфраструктуру мирового сообщества. С каждым годом все большее значение приобретает организация совместных проектов студентов из разных регионов, обмен опытом между преподавателями и учеными. Благодаря глобальной сети мы имеем доступ к различным информационным центрам стран, что в свою очередь развивает возможности для самообразования. В то же время меняются и формы взаимодействия студентов, преподавателей и образовательной среды.

Для того чтобы внедрение Интернет-технологий в образование было успешным, на данный момент необходимо разработать качественно новые методики и программы, необходимо работать с педагогами по популяризации Интернета. Многие учителя убеждены, что они не готовы использовать Интернет-технологии. Однако, по словам Г. Дьюдни и Н. Хокли, большинство из них имеют по крайней мере основные навыки, такие как навигация и поиск информации в Интернете, работа в социальных сетях, общение на форумах, набор текста в базовом текстовом редакторе. Практика показывает, что этого достаточно для организации работы в Интернете со студентами [7, р. 28].

Интернет-технологии предоставляют широкие возможности для межкультурной коммуникации. К таким возможностям относятся устное и письменное общение по электронной почте, блоги, форумы, чаты, организация Интернет-конференций [5]. 
Исходя из всего вышесказанного, можно понять, что Интернет-технологии обладают огромным потенциалом для студентов. Развитие технологий ведет к развитию образовательных возможностей. В настоящее время новые информационно - коммуникационные технологии и различные социальные серверы могут быть использованы для повышения эффективности обучения на уроках английского языка. К таким Интернет-технологиям как средству оптимизации учебного процесса относятся:

1. Подкасты

Подкастинг (англ. podcasting, broadcasting - повсеместное, широкоформатное вещание) - процесс создания и распространения аудио-или видеотрансляций (т.е. подкастов) во всемирной паутине. Обычно каждый подкаст имеет свою конкретную тему и периодичность издания. Подкасты являются хорошей альтернативой телевидению, т.к. они просты в использовании, бесплатны и доступны в любое удобное для пользователя время. Все типы подкастов можно разделить на несколько групп:

- аутентичные подкасты - файлы, содержащие запись речи носителя языка.

- подкасты для преподавателей - подкасты, которые преподаватель создает для учеников сам.

- студенческие подкасты - подкасты, которые студенты записывают чаще всего с помощью преподавателя.

Подкасты показывают реальные ситуации общения, они насыщены живой разговорной речью, знакомят учащихся с историей, культурой, современной жизнью, традициями, обычаями и обычаями стран, изучаемого языка. Это только доказывает методологическую целесообразность использования подкастов на занятиях.

Использование видеоподкастов на уроках английского языка предоставляет большие возможности для изучения этого языка, т.к. данная Интернет-технология имеет ряд преимуществ:

1) предлагаемый видеоматериал является актуальным и достоверным; 
2) видеоподкасты позволяют создавать реальные коммуникативные ситуации для развития устной речи и стимулировать ранее нетренированную речь;

3) информация поступает сразу по двум каналам (звуковому и графическому), что позволяет студентам, лучше запомнить ее;

4) преподаватель экономит время на подготовку к занятиям, т.к. некоторые обучающие видеоподкасты уже разработаны: они сопровождаются заданиями, глоссарием, параллельными текстовыми версиями и интерактивными упражнения.

Таким образом, из всего вышесказанного можно сделать вывод, что видеоподкасты следует использовать на уроках английского языка для оптимизации учебного процесса. Они помогают в совершенствовании навыков говорения, аудирования, приобщении учащихся к особенностям культуры и традиций страны изучаемого языка.

2. Веб-проекты

Веб-проект - это результат объединения проектной методологии с возможностями Интернета.

Эта Интернет-технология является сложным типом задачи. При использовании этой технологии преподаватель должен обладать высоким уровнем предметной и информационной компетентности. Данный вид заданий требует от студента навыков и умений работы с информацией и информационными технологиями. При обучении английскому языку использование заданий на основе электронных ресурсов требует от студентов наличия соответствующего уровня владения языком для работы с аутентичными Интернет-ресурсами [12].

3. Форумы

Данный вид Интернет-технологии представляет собой электронную конференцию с отсроченным доступом к материалам.

Форум - это средство организации и проведения специально организованной самостоятельной деятельности участников форума с координацией преподавателя. Основная цель этой технологии направлена на достижение учебных задач в общении на английском языке и обсуждение различных вопросов, носящих как образовательный, так и неакадемический характер. 
4. Мультимедийный черновик

От английского multimedia scrapbook - «мультимедийный черновик» - это еще одна Интернет-технология, которая представляет собой коллекцию мультимедийных ресурсов. Альбом содержит ссылки на текстовые сайты, аудиофайлы, видеоклипы, графическую информацию и анимационные виртуальные туры, которые сегодня очень популярны. Студенты могут легко скачать и использовать файлы на определенную тему в качестве информационного и иллюстративного материала при изучении определенной темы.

5. Фильмы, сериалы и телепередачи

Многие специалисты утверждают, что подростку практически невозможно запомнить материал без визуальной поддержки [15]. «Их осмысление ориентировано на яркие образы, фрагментарность, лаконичность и необычную, пленительную компоновку материала» $[11$, с. 5646]. Таким образом, фильмы и телепередачи помогут студентам лучше понять активный словарный запас, выучить слова и словосочетания с интересом и большим энтузиазмом.

Согласно этому методу, студенты внимательно смотрят фильм или эпизод дома и выполняют несколько заданий, посвященных новым словосочетаниям и словам: необходимо искать определения данных единиц, а не их перевод. Это помогает понять смысл той или иной лексической единицы и познакомиться с контекстом ее употребления. Выполняя задания по заполнению пробелов, вы фиксируете в памяти лексику и наблюдаете, как она работает в контексте.

Упражнения могут быть основаны на анализе только лексики, словосочетаний и других слов по конкретной теме или могут носить более содержательный характер, например, задания на заполнение пропусков, мини-сообщение о режиссере, краткое изложение содержания фильма, составление предложений с активной лексикой, описание главных героев.

Прежде всего, важно отметить, что студенты испытывают меньшее напряжение и стресс во время изучения иностранного языка во время просмотра фильмов. Это помогает им погрузиться в атмос- 
феру новой реальности, созданной надлежащим образом, проникнуться традициями и обычаями страны изучаемого языка. Визуализация является важной частью процесса обучения. По данным ряда работ Д.А. Рукосуева можно утверждать, что визуализация играет ключевую роль в восприятии и запоминании нового материала [13]. Следовательно, это процесс передачи информации с помощью образов для повышения уровня понимания и соотнесения визуальной формы с любым объектом, предметом или процессом [8].

Учащиеся лучше запоминают слова и словосочетания, и даже повторный просмотр не вызывает большой усталости. Кроме того, фильмы и телепередачи предоставляют студентам менее формальный подход к учебному процессу, что помогает еще лучше мотивировать студентов. Этот опыт показывает, что можно изучать язык с удовольствием и энтузиазмом.

COVID-19 изменил многое в жизни людей по всему миру и, несомненно, сильно повлиял на сферу образования. Популярность внедрения инновационных технологий возросла задолго до пандемии, но именно COVID-19 показал важность готовности как преподавать, так и учиться онлайн.

Во всей учебной программе должны быть учтены такие моменты, как: дистанционное обучение, в ходе которого структура уроков может быть изменена с целью достижения значительного прогресса. В этом случае авторы рассматривают использование Интернет-технологий и фильмов на иностранном языке как превосходную альтернативу студенческим книгам.

Преподавание разговорной речи на занятиях по иностранному языку является одним из важнейших аспектов преподавания английского языка в целом. Помимо понимания иноязычного материала, сегодня студенты должны уметь в полной мере выражать свои мысли на различные темы, демонстрируя при этом свои эмоции, желания и чувства. Проанализировав возможности использования Интернет-технологий для развития навыков устной речи в университет, мы пришли к выводу, что использование таких технологий на уроках английского языка помогает в формировании у студентов 
устной речи, повышает мотивацию к изучению предмета и делает занятия гораздо интереснее, повышая межкультурную компетентность.

Однако для того, чтобы все это действительно произошло, преподаватель английского языка должен найти наиболее эффективные Интернет-технологии, весь материал должен быть тщательно обработан преподавателем.

Таким образом, Интернет-технологии при правильном и корректном использовании развивают устные навыки владения английским языком, повышают уровень словарного запаса и грамматики учащихся, улучшают произношение, оказывают влияние на их психологическое и социальное развитие, помогая студентам стать более разносторонними личностями.

\section{Список литературы}

1. Колкер Я.М. Практичекая методика обучения иностранному языку. М.: Академия, 2000. 264 с.

2. Кудинова В.И., Храмченко Д.С., Титова О.А., Головина И.В. От слова к речи: учебно-методическое пособие. Тула: Имидж-Принт, 2018. $50 \mathrm{c}$.

3. Кудинова О.А. Формирование иноязычной коммуникативной компетенции с использованием инновационных технологий // Инновационный потенциал урока английского языка: от теории к практике (From Reflection to Action): материалы Международной научно-практической конференции для преподавателей английского языка. 20-22 сентября 2013 г. Тула: Гриф и К, 2013. С. 132-136.

4. Орлов Г.А. Современная английская речь: Учеб. пособие для вузов по спец. «Англ. яз. и лит.». М.: Высш. шк., 1991. 240 с.

5. Полат Е.С. Новые педагогические и информационные технологии в системе образования: Учеб. пособие для студ. пед. вузов и системы повыш. квалиф. пед. кадров. М.: Академия, 1999. 224 с.

6. Титова О.А., Кудинова В.И., Родионова И.В., Головина И.В. Инновационные технологии в преподавании иностранных языков: учебно-методическое пособие. Тула: Имидж-Принт, 2019. 54 с. 
7. Dudeney G., Hockly N. How to Teach English with Technology. Pearson Education Limited, 2008. 192 p.

8. Isayeva E. The new generation of students: psychological particularities, learning motivation and the difficulties during the learning process of the 1st year student // Medical Psychology in Russia: online scientific journal, 9 March 2015. URL: https://medpsy.ru (дата обращения: 18.11.2020).

9. Kudinova O.A., Khramchenko D.S., Kudinova V.I., Davydova M., Akimtseva Y.V. Analytical reading as a way to improve professional competence of EFL learners: linguistic aspects \& teaching methodology. ICERI2018 Proceedings, pp. 9043-9048.

10. Kudinova O.A, Kudinova V.I., Fiction literature as a means of developing critical thinking and both universal and general cultural competences of undergraduates // ICERI2020 Proceedings, pp. 4877-4885.

11. Mammadova N., Pogrebnaya A. The use of the instagram platform and text messengers in the context of contemporary education // EDULEARN19 Proceedings, pp. 5646-5650.

12. Podcast in English. URL: https://podcastsinenglish.com/pages1/level1. shtml (дата обращения: 11.11.2020).

13. Rukosuyeva D. The particularities of knowledge perception with the use of methods of visualization // Youth and science: the materials of XI Russian scientific conference of students, post-graduates and young scientists with international participation. 2010. Vol. 1, pp. 136-138.

14. Sanchez A.V., Ruiz M.P. Competence-Based Learning. A proposal for the assessment of generic competences. Bilbao: University of Deusto Press, 2008. 335 p.

15. Shved O.V. Visual communication in the modern world // Literature, language and culture influences by globalization: Monograph, 2015. Vol. 7. Vienna: "East West" Association for Advanced Studies and Higher Education GmbH, pp. 70-82.

\section{References}

1. Kolker Ya.M. Prakticheskaya metodika obucheniya inostrannomu ya$z y k u$ [Practical methods of teaching a foreign language]. Moscow: Akademiya, 2000. 264 p. 
2. Kudinova V.I., Hramchenko D.S., Titova O.A., Golovina I.V. Ot slova $k$ rechi [From word to speech]. Tula: Imidzh-Print, 2018. $50 \mathrm{p}$.

3. Kudinova O.A. Formirovanie inoyazychnoj kommunikativnoj kompetencii s ispol'zovaniem innovacionnyh tekhnologij [Formation of foreign language communicative competence using innovative technologies]. Innovacionnyj potencial uroka anglijskogo yazyka: ot teorii k praktike (From Reflection to Action): materialy Mezhdunarodnoj nauchno-prakticheskoj konferencii dlya prepodavatelej anglijskogo yazyka. 20-22 sentyabrya $2013 \mathrm{~g}$ [Innovative potential of an English lesson: from theory to practice (From Reflection to Action): materials of the International scientific-practical conference for teachers of English. September 20-22, 2013]. Tula: Grif i K, 2013. P. 132-136.

4. Orlov G.A. Sovremennaya anglijskaya rech' [Modern English speech]. Moscow: Vyssh.shk., 1991. 240 p.

5. Polat E.S. Novye pedagogicheskie i informacionnye tekhnologii v sisteme obrazovaniya [New pedagogical and information technologies in the education system]. Moscow: Akademiya, 1999. 224 p.

6. Titova O.A., Kudinova V.I., Rodionova I.V., Golovina I.V. Innovacionnye tekhnologii v prepodavanii inostrannyh yazykov [Innovative technologies in teaching foreign languages]. Tula: Imidzh-Print, 2019. $54 \mathrm{p}$.

7. Dudeney G., Hockly N. How to teach English with technology. Pearson Education Limited, 2008. 192 p.

8. Isayeva E. The new generation of students: psychological particularities, learning motivation and the difficulties during the learning process of the 1st year student. Medical Psychology in Russia: online scientific journal, 9 March 2015. URL: https://medpsy.ru

9. Kudinova O.A., Khramchenko D.S., Kudinova V.I., Davydova M., Akimtseva Y.V. Analytical reading as a way to improve professional competence of EFL learners: linguistic aspects \& teaching methodology. ICERI2018 Proceedings. P. 9043-9048.

10. Kudinova O.A., Kudinova V.I. Fiction literature as a means of developing critical thinking and both universal and general cultural competences of undergraduates. ICERI2020 Proceedings. P. 4877-4885. 
11. Mammadova N., Pogrebnaya A. The use of the instagram platform and text messengers in the context of contemporary education. EDULEARN19 Proceedings, 2019. P. 5646.

12. Podcast in English. URL: https://podcastsinenglish.com/pages1/level1. shtml

13. Rukosuyeva D. The particularities of knowledge perception with the use of methods of visualization. Youth and science: the materials of XI Russian scientific conference of students, post-graduates and young scientists with international participation. 2010. Vol. 1. P. 136-138.

14. Sanchez A. V., Ruiz M. P. Competence-Based Learning. A proposal for the assessment of generic competences. Bilbao: University of Deusto Press, 2008. 335 p.

15. Shved O.V. Visual communication in the modern world. Literature, language and culture influences by globalization: Monograph, 2015. Vol. 7. Vienna: "East West" Association for Advanced Studies and Higher Education GmbH, pp. 70-82.

\section{ДАННЫЕ ОБ АВТОРЕ}

Кудинова Ольга Андреевна, ассистент кафедры английского языка

Тульский государственный педагогический университет им. Л.Н. Толстого

пр. Ленина, 125, г. Тула, Тульская область, 300026, Российская Федерачия

walwow@bk.ru

\section{DATA ABOUT THE AUTHOR}

Kudinova Olga Andreevna, Assistant Lecturer, Department of the English Language

Tula State Leo Tolstoy Pedagogical University

125, Lenin Ave., Tula, Tula Region, 300026, Russian Federation walwow@bk.ru

SPIN-code: 1297-4253

ORCID: 0000-0001-9731-8389 